\title{
BMJ Open Recent trends in seroprevalence of rubella in Korean women of childbearing age: a cross-sectional study
}

\author{
Rihwa Choi (D) , ${ }^{1,2}$ Yejin Oh, ${ }^{1}$ Youngju Oh, ${ }^{1}$ Sung Ho Kim, ${ }^{1}$ Sang Gon Lee, ${ }^{1}$ \\ Eun Hee Lee ${ }^{3}$
}

To cite: Choi R, Oh Y, Oh Y, et al. Recent trends in seroprevalence of rubella in Korean women of childbearing age: a crosssectional study. BMJ Open 2020;10:e030873. doi:10.1136/ bmjopen-2019-030873

- Prepublication history for this paper is available online. To view these files, please visit the journal online (http://dx.doi. org/10.1136bmjopen-2019030873).

Received 04 April 2019 Revised 01 August 2019 Accepted 29 August 2019

Check for updates

(C) Author(s) (or their employer(s)) 2020. Re-use permitted under CC BY-NC. No commercial re-use. See rights and permissions. Published by BMJ.

${ }^{1}$ Laboratory Medicine, Green Cross Laboratories, Yongin, Republic of Korea

${ }^{2}$ Laboratory Medicine and Genetics, Samsung Medical Center, Sungkyunkwan University School of Medicine, Gangnam-gu, Republic of Korea ${ }^{3}$ Green Cross Laboratories, Yongin, Republic of Korea

\section{Correspondence to}

Dr Sang Gon Lee, Green Cross Laboratories, Yongin, Gyeonggido, Republic of Korea;

sglee@gclabs.co.kr

Dr Eun Hee Lee, Green Cross Laboratories, Yongin, Gyeonggido, Republic of Korea; ehlee@gclabs.co.kr

\section{ABSTRACT}

Objectives The aim of this study was to investigate the immunity against rubella using the serological status of rubella-specific $\lg G$ antibodies (antirubella $\lg G$ ) in Korean women of childbearing age (15-49 years).

Design Retrospective cross-sectional study.

Setting Population-based cross-sectional study in South Korea.

Participants Between January 2010 and December 2017, test results from Korean women aged 15-49 years who had visited an obstetric private clinic (nationwide institutions) and had requested rubella-specific $\lg G$ antibody tests from Green Cross Laboratories were obtained from the laboratory information system.

Results Between 2010 and 2017, antirubella IgG test results from 328426 Korean women aged 15-49 years who had visited private obstetric clinics (1438 institutions nationwide) were retrospectively analysed by tested year, age, cohort and geographic regions. Over the 8-year study period, the rate of unimmunised women ranged from $7.8 \%$ to $9.7 \%$. Multivariable-adjusted logistic regression models showed that the odds of being immune to rubella (positive and equivocal results of antirubella IgG test) were lower in 2017 compared with 2010, in women in their 40s, in a pre-catch-up cohort and in women living in Incheon, Busan, South Gyeongsang, North and South Jeolla and Jeju provinces $(p<0.0001)$.

Conclusions In consideration of the factors associated with prevalence of women unimmunised to rubella, future public health efforts should be focused on catchup activities. The results of this study could be used to strengthen disease control and prevent rubella, including a nationwide immunisation programme.

\section{INTRODUCTION}

Rubella disease is caused by rubella virus (belonging to the family Togaviridae and the only member of the genus Rubivirus). Although most cases of infection lead to a mild, self-limiting measles-like disease, the real threat arises when rubella virus infects the fetus, particularly during the first trimester when infection can lead to miscarriage or congenital rubella syndrome. Worldwide, over 100000 babies are born with congenital rubella syndrome every year,

\section{Strengths and limitations of this study}

- The main strength of the study lies in its sample size, due to the fact that it is a nationwide study with one of the broadest samples to date in South Korea.

- The study provided a recent information of the seroprevalence of antirubella IgG that have not been available at this scale before.

- The huge sample size of this study allowed for precise information of the age-related seroprevalence of antirubella IgG and this study provides valuable information for establishing a catch-up vaccination programme in South Korea

- One limitation of this study was the lack of detailed clinical information; however, seroprevalence studies are an essential tool to monitor the efficacy of vaccination programmes, to understand population immunity and to identify populations at higher risk of infection.

and the WHO recommends that all countries that have not yet introduced a rubella vaccine should consider doing so using existing, well-established measles immunisation programmes. ${ }^{2}$ The WHO Strategic Advisory Group of Experts on Immunization (SAGE) recommends an increased focus on improving national immunisation systems in general to better control rubella. ${ }^{2}$ Under the Global Vaccine Action Plan 2011-2020, rubella is targeted for elimination in five WHO Regions by $2020 .{ }^{34}$ As has been reported in Europe, suboptimal coverage levels in childhood $(<95 \%)$ can lead to a prolonged interepidemic period and to a paradoxical shift of disease incidence towards older age groups, including women of childbearing age, with a consequent increase of congenital rubella syndrome. ${ }^{5}$ Serosurveys may represent an effective instrument to measure infectioninduced and vaccine-induced immunity in a specific population, and serosurveys can effectively support strategies aimed at eliminating the disease. ${ }^{5}$ 
The incidence of rubella infection in South Korea was 107 cases in 2000 that decreased to 7 cases in 2017, corresponding to incidence rates below 0.1 per 100000 persons according to the Infectious Diseases Surveillance Yearbook, 2017. ${ }^{6}$ Although the exact number of cases for congenital rubella syndrome was not available for the surveillance book, 17 cases in 2010 of congenital rubella syndrome were reported, which using the Korean Classification of Disease code P350 for congenital rubella syndrome on the Healthcare Bigdata Hub by the Health Insurance Review and Assessment Service (HIRA). ${ }^{7}$ According to the reported measles and rubella cases and incidence rates by WHO member states, 0-3947 confirmed rubella cases corresponding to incidence rates of $0-11.54$ per 1000000 total population were reported in 2018 in the western pacific region. ${ }^{8}$

In Korea, a rubella vaccination programme using the measles, mumps in rubella (MMR) vaccine has been included in the national immunisation programme since 1985 for disease control and prevention. ${ }^{9}$ A second MMR vaccine dose was introduced in 1997, and a catch-up measles-rubella (MR) vaccine for school-aged children was introduced in 2001. ${ }^{9}$ In 2002, a two-dose MMR keep-up programme through the verification of vaccination history was introduced at elementary schools (6-7 years).$^{9}$ A new vaccination policy was formed by the 2012 Military Healthcare Service, and since then, MMR vaccines have been routinely administered to all new recruits early in basic training. ${ }^{10}$ The national guidelines in Korea regarding ascertainment of rubella immunity are based on laboratory evidence for rubella antibodies and the Korea Centers for Disease Control and Prevention recommends that women of childbearing age whose antirubella specific IgG is negative should receive 1 dose of the MMR vaccine although they did have histories of rubella vaccination (total numbers of vaccination in one individual should be $\leq 3) .{ }^{11}$

Although there have been several studies on rubella in Korea, most of the studies have only been focused on surveillance of newly identified cases, seroprevalences of rubella IgG in children or had been conducted in the early 1990s. ${ }^{9}{ }^{10}{ }^{12-16}$ Although a recent meta-analysis assessing global seroprevalence of rubella among pregnant and childbearing age women, no data from Korean populations were included in the study. ${ }^{5}$ In a recent 16-year review of seroprevalence studies on rubella, only one Korean study on children and adolescents was included. $^{3}$ To our knowledge, no recent data have been collected on rubella immunisation status with rubellaspecific IgG antibodies in Korean women of childbearing age in a large study population, which could provide basic knowledge on nationwide immunisation strategies. Green Cross Laboratories is one of the largest referral clinical laboratories throughout South Korea that has its own biologistics and provides clinical specimen analysis services including rubella-specific IgG antibody tests to nationwide clinics and hospitals. According to the provider data on the National Health Insurance Statistical Yearbook 2017 published by HIRA in South Korea, 1319 private obstetric clinics and 1433 hospitals with or without obstetric clinics are providing health services. ${ }^{17}$ Among a total of 91545 healthcare providing institutions (public and private), $4.1 \%$ (3746 institutions) were public or national provider institutions. ${ }^{17}$ According to the review records of delivery by provider type in the same book, $89.9 \%$ (523/582) of delivery institutions nationwide were private obstetric clinics and hospitals. ${ }^{17}$ Among the 358285 deliveries carried out in 2017, 93.5\% (335 119) were delivered in private obstetric clinics and hospitals. ${ }^{17}$

Therefore, in this study, we aimed to investigate the immunity against rubella and to share baseline data for future immunisation policies in South Korea. The aim of this study was to investigate the epidemiology of rubella immunisation status using serological assays for rubellaspecific IgG antibodies in Korean women of childbearing age. In addition, we assessed rubella immunisation status according to year and age group.

\section{MATERIALS AND METHODS}

\section{Participants' involvement and data collection}

No patients were involved in the development of the research question or the outcome measures, nor were they involved in developing plans for design or implementation of the study. No patients were asked for advice regarding the interpretation or writing of results. There are no plans to disseminate the study results to the relevant patient community.

\section{Study populations}

Between January 2010 and December 2017, test results from Korean women aged 15-49 years who had visited an obstetric private clinics and hospitals (nationwide institutions) and had requested rubella-specific IgG antibody tests from Green Cross Laboratories were obtained from the laboratory information system. Missing data for age, sex and geographic regions were excluded. Test results from women whose tests were duplicated were excluded. All data were anonymised before being transferred to analysis for age-specific, year-specific, birth cohort and geographical region-specific antirubella IgG seroprevalences. This study was conducted according to guidelines in the Declaration of Helsinki.

\section{Data collection}

Annual incidence of rubella infection in South Korea was obtained from reported cases in the Infectious Diseases Surveillance Yearbook, 2017 by the Korea Centers for Disease Control and Prevention. ${ }^{6}$ Data for the incidence of congenital rubella syndrome was obtained from the Healthcare Bigdata Hub by HIRA using Korean Classification of Disease code P350 in South Korea. ${ }^{7}$

\section{Analytical procedures}

All serum samples were tested for antirubella IgG using a chemiluminescent microparticle immunoassay 
(Architect i2000SR, Abbott Diagnostics, Abbott Park, Illinois, USA) according to the manufacturer's instructions. For the rubella IgG assay, the presence of $\geq 10 \mathrm{IU} / \mathrm{mL}$ was defined as 'positive'. Antibody levels of $0.0-4.9 \mathrm{IU} / \mathrm{mL}$ were defined as 'negative', and antibody levels between 5.0 and $9.9 \mathrm{IU} / \mathrm{mL}$ were defined as 'equivocal'. During the 8-year study period, the laboratory protocol was maintained without any changes and all tests requested for antirubella specific IgG were analysed automatically and tested once without retest.

\section{Definition}

Positive rubella-specific IgG results are indicative of past exposure to rubella virus or being vaccinated. ${ }^{18}$ Women who had 'negative' results were defined as 'unimmunised'. Women were classified as 'immune' if their antirubella IgG was positive or showed equivocal results. ${ }^{18}$ Birth cohorts were defined based on the vaccination programme: pre-catch-up, 1976-1984; catch-up, 19851993 and keep-up, $\geq 1994 .{ }^{9}$ The pre-catch-up (1976-1984) cohort was women who had presumptively limited MMR vaccination coverage with only one dose provided by the public programme. The catch-up (1985-1993) cohort was woman who had limited MMR vaccination coverage but were given the MR vaccine during the 2001 catch-up campaign. ${ }^{9}$ The keep-up ( $\left.\geq 1994\right)$ cohort was women who were candidates for the keep-up programme. ${ }^{9}$

\section{Statistical analysis}

Categorical variables are presented as frequencies and percentages. The $\chi^{2}$ test was used to compare categorical variables. The Cochran-Armitage test for trend was performed to evaluate the seroprevalence of antirubella IgG by year and cohort. Multivariable-adjusted logistic regression models were used to estimate the OR of being immune to rubella based on the results of the antirubella IgG seroprevalence test for the tested years, age, birth cohort and geographic region in South Korea. Variables with univariate $\mathrm{p}$ values less than 0.05 were included as adjusted variables for the multivariable analysis. Statistical analysis was executed using MedCalc Statistical Software V.18.5 (MedCalc Software bvba, Ostend, Belgium). P values were considered significant at the 0.05 level.

\section{RESULTS}

\section{General characteristics of the study population}

Between January 2010 and December 2017, antirubella IgG test results from 328426 Korean women age 15-49 years who had visited obstetric private clinics (from 1438 institutions nationwide) and had requested rubellaspecific IgG antibody tests from Green Cross Laboratories were obtained from the laboratory information system and included in the study. The numbers for antirubella IgG results for the study subjects by each year and age group are summarised in table 1.

\section{Rubella immunity in Korean women of childbearing age}

The overall proportion of IgG-negative women who were defined as 'unimmunised' was $8.6 \%$, and the overall proportion of IgG-equivocal women was $15.0 \%$ and IgGpositive women was $76.4 \%$. Rubella-specific IgG antibody test results with an annual incidence of rubella infection and congenital rubella syndrome from surveillance data by year are summarised in figure 1 . There were significant differences in the rate of unimmunised women during the 8-year study period $(\mathrm{p}<0.05)$, although there was no significant trend $(p>0.05)$. There was a decrease in the rate of women who had positive rubella-specific IgG antibody results (from $81.0 \%$ in 2010 to $73.0 \%$ in 2017 , $\mathrm{p}<0.05)$ and an increase in the rate of women who had 'equivocal' results from 2010 to 2017 (11.0\% in 2010 to $17.6 \%$ in $2017, \mathrm{p}<0.05$, figure 1$)$. There were significant differences in the rate of unimmunised women among different age groups, cohorts and geographic regions $(\mathrm{p}<0.05)$. For example, less than 1000 women had been tested for antirubella IgG in the Gangwon province and Ulsan.

Multivariable-adjusted logistic regression models showed that the odds of being immune to rubella (positive and equivocal results of antirubella $\mathrm{IgG}$ tests) were decreased in 2017 compared with 2010 (OR 0.63, 95\% CI 0.60 to $0.67, \mathrm{p}<0.0001)$ and women in their $40 \mathrm{~s}$ (OR 0.85 , $95 \%$ CI 0.79 to $0.90, \mathrm{p}<0.0001$, table 2). Among different cohorts, catch-up (being born in 1985-1993) and keep-up (born $\geq 1994$ ) cohorts had higher ORs for being immune to rubella compared with pre-catch-up cohorts (born in 1976-1984, $\mathrm{p}<0.0001)$. Among different geographic regions, women living in Incheon, Busan, South Gyeongsang, North and South Jeolla and Jeju provinces had lower ORs and women living in Sejong city and Daejeon had higher ORs for being immune to rubella in comparison with women living in Seoul $(\mathrm{p}<0.0001)$.

\section{DISCUSSION}

In this study, we investigated the seroprevalence of rubella in Korean women of childbearing age within the past 8 years. The strength of this study was the large study population over a long study period (8 years) and the novelty of the study population (Korean women of childbearing age were assessed for the first time in Korea). Because previous studies focused on the different measurement methods and immunisation status, this suggested that equivocal results might be due to being immune to rubella infection; ${ }^{18} 19$ thus, the authors focused on and analysed factors associated with those whose antirubella IgG results were negative.

Understanding the spread of infectious diseases and designing optimal control strategies is a major goal of public health. ${ }^{20}{ }^{21}$ In the present study, the seronegativity prevalence was $8.6 \%$ in Korean women of childbearing age. A recent 16-year review of seroprevalence studies on rubella assessing 97 articles between January 1998 and June 2014 had reported that seroprevalence ranged from $53.0 \%$ to $99.3 \%$ for rubella studies. ${ }^{3}$ A recent metaanalysis of rubella among pregnant and childbearing age women had reported that approximately $88 \%$ of the 


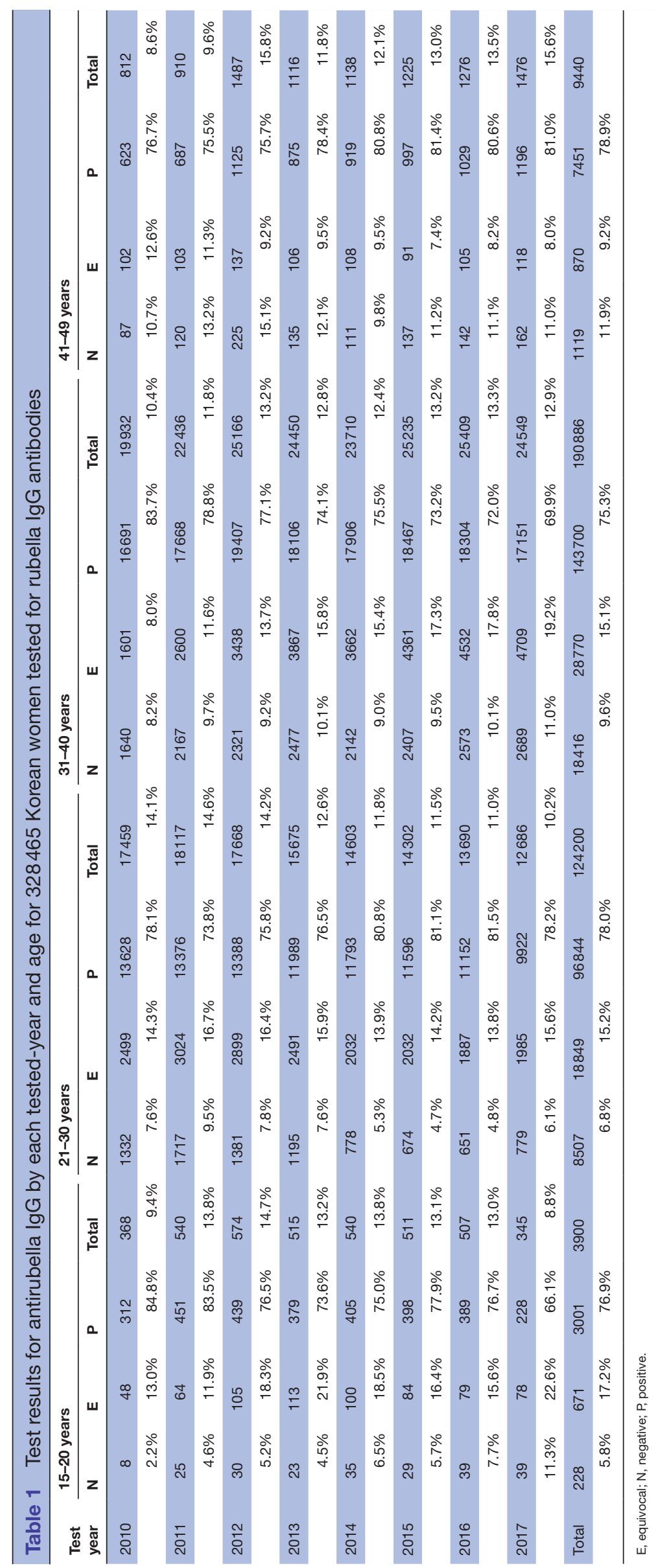




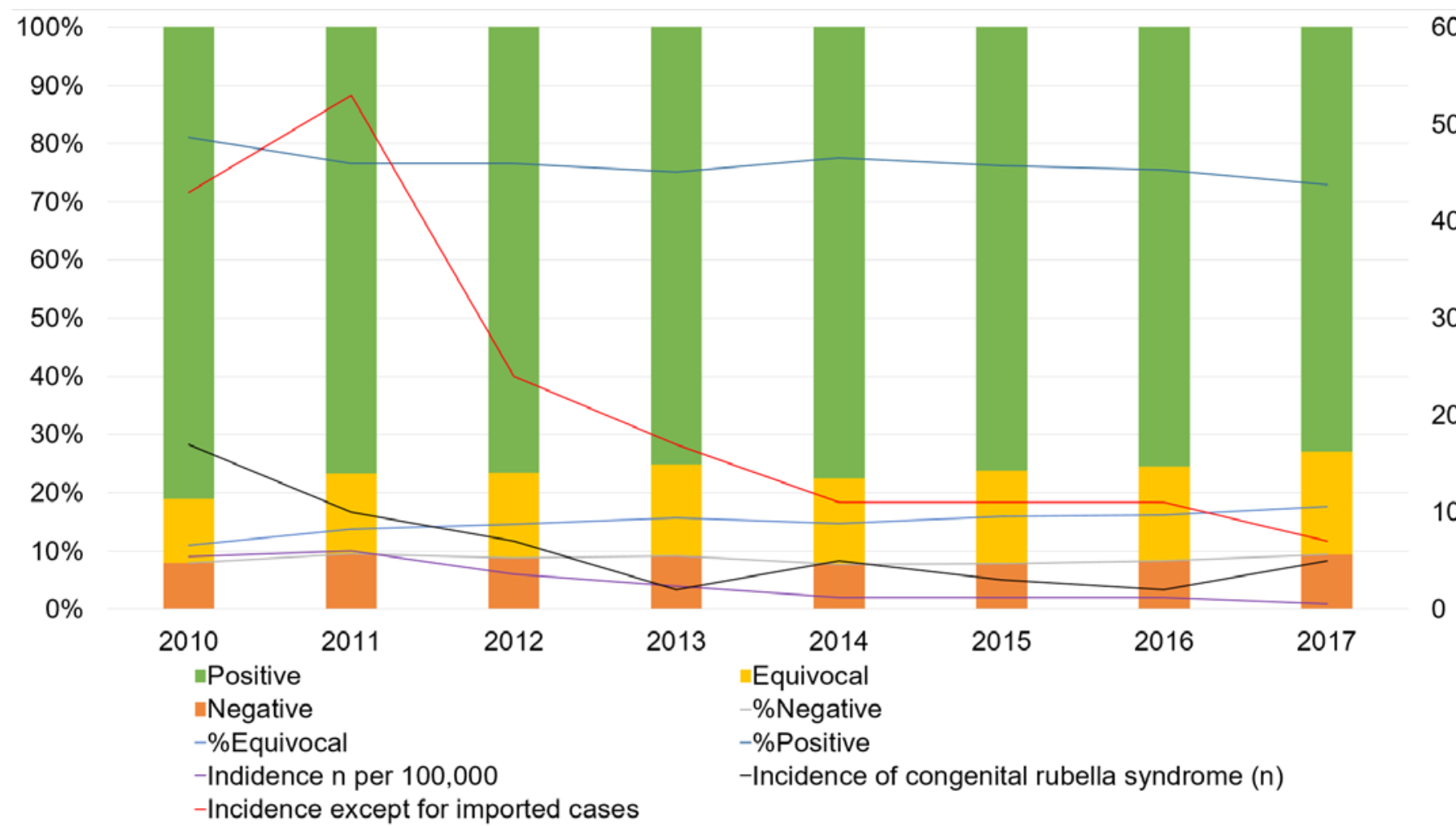

Figure 1 Rubella-specific IgG antibody test results with annual incidence of rubella infection and congenital rubella syndrome from surveillance data by year (2010-2017). Percentage of rubella specific IgG results in this study (left axis) and numbers of cases for incidence of rubella from surveillance data (right axis) are plotted against years tested.

studies conducted on pregnant women had reported a seronegativity rate $>5 \%$, and the pooled rubella seronegativity prevalence was $9.3 \% .^{5}$ The study had reported that global seronegativity prevalence was of concern, considering that WHO set the rubella susceptibility threshold at $5 \%$ for women of childbearing age. Previous studies that had been included in the meta-analysis had used more than 1000 subjects and had been published within the past 10 years are summarised in table 3 .

The seroprevalence of rubella in Korean populations was assessed previously in infants, children and adolescents. ${ }^{12-16}$ One study on 5393 students from eight elementary schools in the Gyeonggi province, Korea in 1993, 1996 and 1996 had reported that the age-adjusted rubella susceptibility rate was $22.9 \% .{ }^{14}$ Another study performed during the same study period had reported that rubella antibody loss rates were $14.3 \%-15.8 \%$ in Korean children. ${ }^{12}$ In a 2005 population-based survey in Nonsan, Korea, age-appropriate immunisation among urban-rural children aged 24-35 months had reported that the ageappropriate MMR immunisation rate was $61.1 \%-97.4 \%{ }^{16}$ A recent study conducted between September 2009 and December 2010 assessing seroprevalence of rubella in 295 infants and 80 of their mothers had reported that seropositive rates were $22.4 \%$ in infants and $98.8 \%$ in mothers $(79 / 80) \cdot{ }^{13}$ In that study, because none of the infants had a history of MMR vaccination, natural infection or contact with an infected person, it was assumed that specific antibodies were passed from their mothers to their infants. ${ }^{13}$
Moreover, among the 80 mothers, 55 (68.8\%) had experienced either immunisation or past rubella infection. ${ }^{13}$

The historical immunisation coverage in preschool children right before admission to elementary school, which was evaluated based on a telephone survey, reported $99.5 \%$ in 2001 and $97.3 \%$ of school-aged children (catch-up cohort) were vaccinated with the MR vaccine. ${ }^{22}$ According to the Infectious Disease Surveillance Yearbook 2017, published by the Korean Ministry of Health and Welfare and the Korean Centers for Disease Control and Prevention, the incidence rate of rubella from 2001 to 2017 decreased (from 0.17 per 100000 population in 2001 to 0.01 per 100000 population in 2017). ${ }^{6}$ In this study, ORs for being immune to rubella infection were higher in the catch-up (born 1985-1993) and keep-up (born $\geq 1994$ ) cohorts than in pre-catch-up cohorts (born 1976-1984) which suggests that catch-up and keep-up immunisation was effective. ${ }^{22}$ The vaccine coverage rate was maintained at $>95 \%$ from 2010 to 2017 in South Korea (ranges $97.0 \%$ in 2012 to $99.8 \%$ in 2010).$^{22}$ No rubella outbreak had been reported in South Korea over 8 years (2010-2017) according to the Infectious Disease Surveillance Yearbook. Among the different age groups, older women were more likely to have negative IgG results and no protection from rubella infection. Women in their 30s had the lowest rate of IgG+ results in this study. According to recent data from Korean Statistical Information (KOSIS), the average maternal age at delivery for Korean women was 32.4 years in 2016. 
Table 2 Association between seroprevalence of antirubella lgG (being immune to rubella) ${ }^{\star}$ and population characteristics

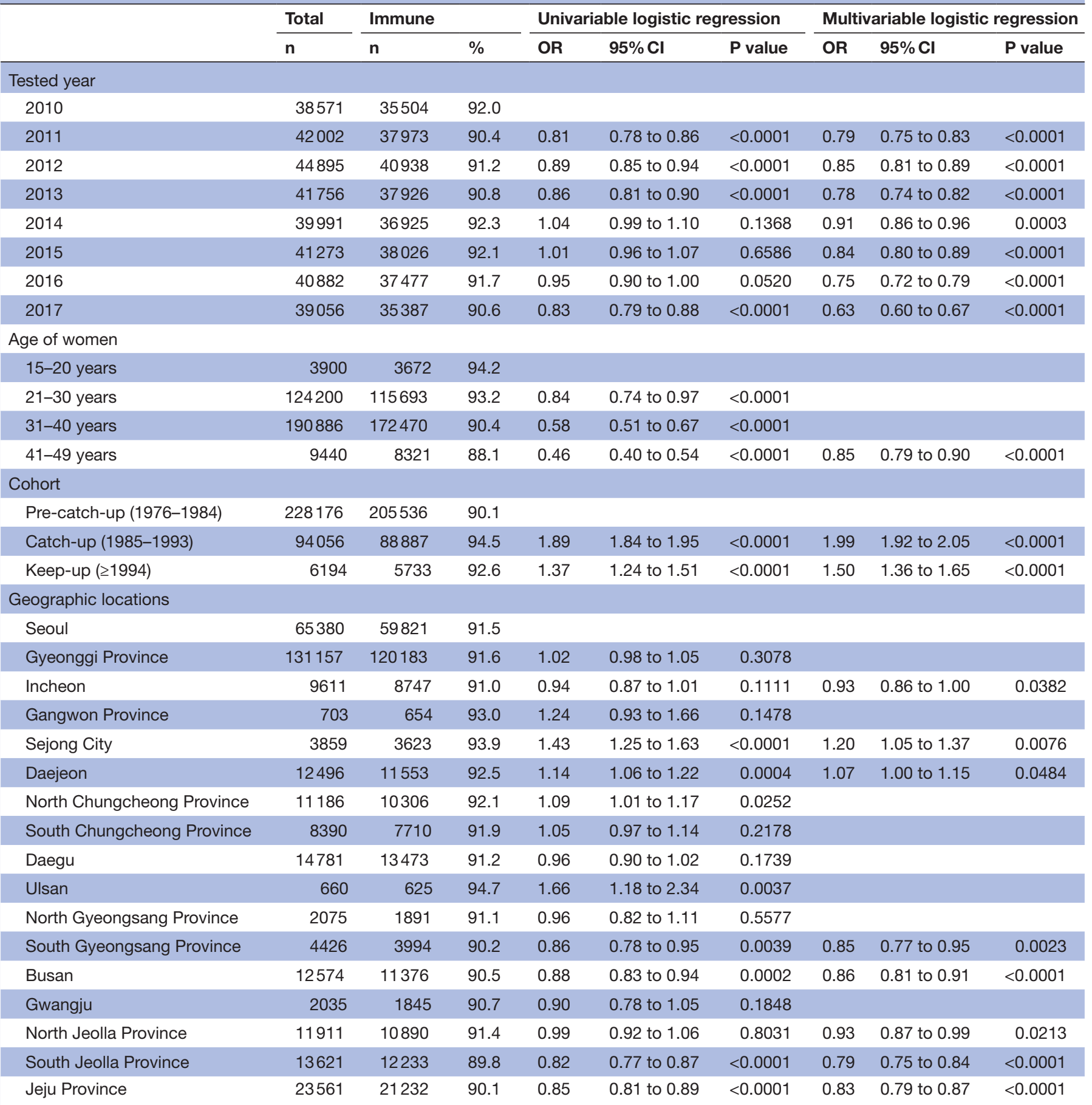

*Positive and equivocal results of antirubella specific lgG test results were defined as 'immune' in this study. ${ }^{18}$

Because of this, public health efforts should be focused on catch-up activities. The results of this study could be used as basic knowledge to support strengthening disease control and prevention of rubella, including a nationwide immunisation programme.

In South Korea, national guidelines in force to control and prevention measles and rubella include national immunisation programme and active disease surveillance system. ${ }^{2422}$ MMR vaccination has been covered by national health insurance that provides free of charge immunisation to all children aged $\leq 12$ years, and clinical laboratory screening for rubella immunisation status using antirubella-specific IgG tests in pregnant women has been covered by the national health insurance free of charge for women visiting obstetrics clinics. ${ }^{17}$ Susceptible woman of childbearing age is indeed a priority, and public health efforts should be focused on catch-up activities in order to reduce the rate of susceptible young adults, especially for all women of childbearing age. ${ }^{23}$ Gynaecologists and general practitioners should be 


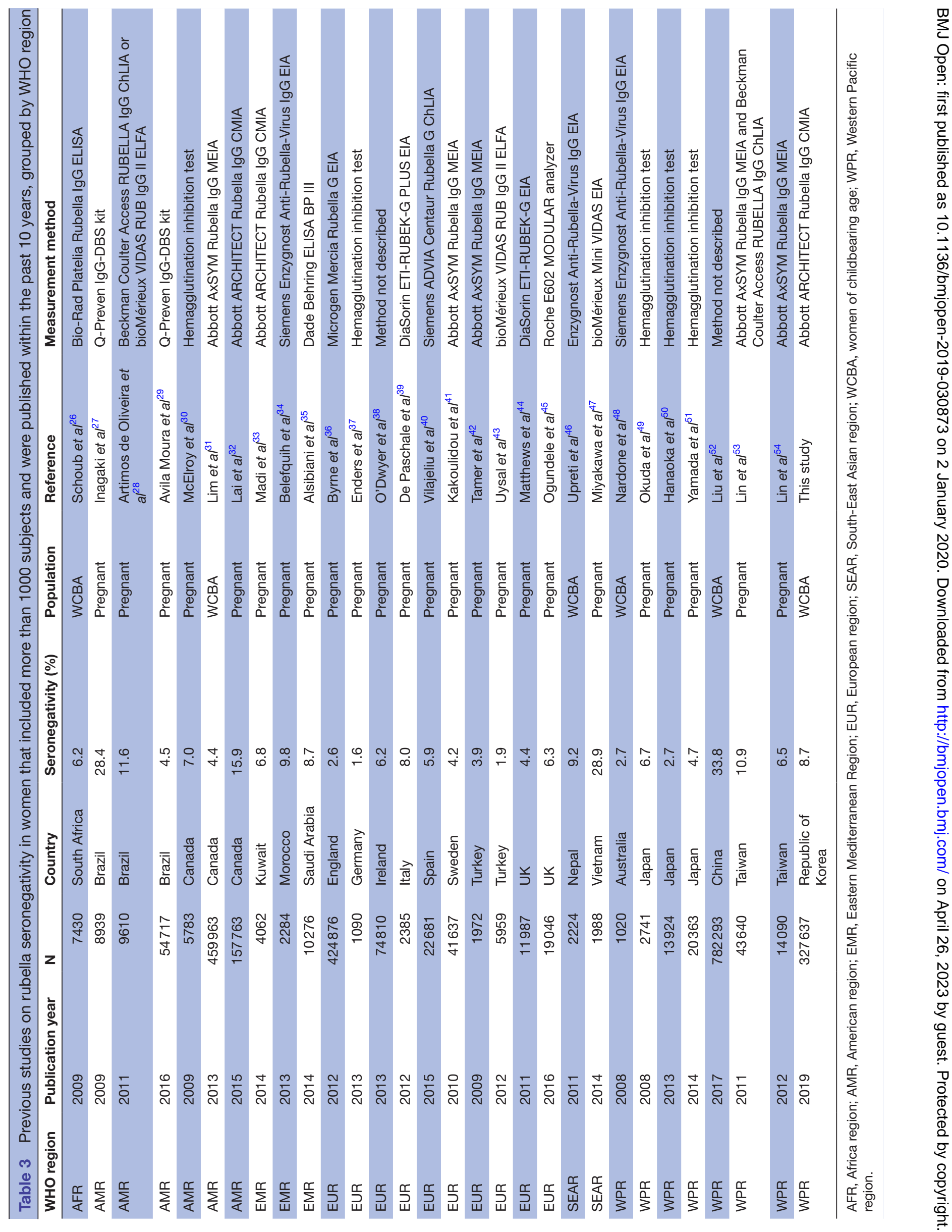


encouraged to propose rubella screening for women of childbearing age before they become pregnant to identify those women who lack rubella antibodies, whether acquired as the result of vaccination or a natural infection. ${ }^{23}$ Finally, active surveillance from laboratories that perform rubella immunity testing should be planned; laboratories should notify the Public Health Authority about every woman of childbearing age with a negative test, and the Public Health Authority should engage these women to promote immunisation against rubella. ${ }^{23}$ Serological surveillance is an important tool for the evaluation of vaccination programmes and avoids the limitations of passive disease reporting systems; this is one of the entry points for congenital rubella syndrome surveillance, where gaps limit the ability to monitor progress towards its elimination. ${ }^{23}$

In this study, women living in Sejong city were the most protected from rubella infection. In early 2007 , the South Korean government had created a special administrative district from parts of the South Chungcheong and North Chungcheong provinces, near Daejeon, to relocate nine ministries and four national agencies from Seoul. Various government programmes for encouraging more births, such as incentives, in different regions may have affected the results. ${ }^{4}$ In this study, less than 1000 women had been tested for antirubella IgG in the Gangwon province and Ulsan. This may affect the per cent seropositivity of antirubella IgG in the present study. Future studies are needed to define the effect of regional differences of government strategies on rubella seroprevalences.

One limitation of this study was the lack of clinical information, such as vaccination history or contact history with rubella-infected individuals. The results of this study were prone to ascertainment bias because the study population was based on mostly private obstetric clinics; thus, results might be different from those obtained from individuals using national or public healthcare providing institutions, although the use of a population-based study minimised selection bias. ${ }^{24}$ Because the exact proportions of pregnant women in Korea who used public health facilities to test for antirubella IgG, and their sociodemographics as well as rubella vaccine coverage among the population seeking healthcare from private and public sectors and the proportion of pregnant women as well as the general population seeking care from the private sector across provinces were not available, future studies to evaluate those factors associated with rubella control and prevention are needed. However, we do not yet understand what surrogate markers, other than antibodies, show longer-term cell-mediated immunity and protection from disease. ${ }^{1}$ Seroprevalence studies are an essential tool to monitor the efficacy of vaccination programmes, to understand population immunity and to identify populations at higher risk of infection. ${ }^{25}$ This study is a cross-sectional study and merely descriptive analyses were adopted in this study. The results of this study were prone to ascertainment bias. The present study did not include men, women with older ages or foreigners living in South Korea. Therefore, the findings are not generalisable to these groups. A systems-level approach to understanding the development and maintenance of acute and long-term immunity to rubella and a rubella-containing vaccine is needed. ${ }^{1}$

\section{CONCLUSION}

In conclusion, this study investigated immunisation status of rubella among Korean women of childbearing age. Considering the immunisation status by age group and the increased prevalence of women with equivocal results, future public health efforts should be focused on catch-up activities. The results of this study could be used as foundational knowledge for strengthening disease control and prevention of rubella, including a nationwide immunisation programme.

Contributors All authors contributed to manuscript preparation. RC and SGL: conception, design, statistical analyses and interpretation of the data. RC, YoO, SHK and SGL: data acquisition. RC: article drafting. RC, SGL and EHL: critical article revision for important intellectual content. SGL and EHL: obtaining funding. RC, YoO, YeO and SHK: administrative and technical support. RC, YoO and SHK: collection and assembly of data. All authors read and approved the final manuscript.

Funding This work was supported by Abbott Diagnostics Korea.

Disclaimer The sponsor had no involvement in the study design, data interpretation, or writing of the manuscript.

Competing interests None declared.

Patient consent for publication Not required.

Ethics approval All procedures involving human subjects were approved by the Institutional Review Board of Green Cross Laboratories (GCL 2017-1010-02).

Provenance and peer review Not commissioned; externally peer reviewed. Data availability statement Data are available on reasonable request.

Open access This is an open access article distributed in accordance with the Creative Commons Attribution Non Commercial (CC BY-NC 4.0) license, which permits others to distribute, remix, adapt, build upon this work non-commercially, and license their derivative works on different terms, provided the original work is properly cited, appropriate credit is given, any changes made indicated, and the use is non-commercial. See: http://creativecommons.org/licenses/by-nc/4.0/.

ORCID iD

Rihwa Choi http://orcid.org/0000-0002-8266-2248

\section{REFERENCES}

1 Lambert N, Strebel P, Orenstein W, et al. Rubella. Lancet 2015;385:2297-307.

2 World Health Organization. WHO fact sheet for rubella 2017. Available: https://www.who.int/en/news-room/fact-sheets/detail/ rubella [Accessed Jan 2019].

3 Dimech W, Mulders MN. A 16-year review of seroprevalence studies on measles and rubella. Vaccine 2016;34:4110-8.

4 World Health Organization. Global measles and rubella strategic plan 2012, 2012.

5 Pandolfi E, Gesualdo F, Rizzo C, et al. Global seroprevalence of rubella among pregnant and childbearing age women: a metaanalysis. Eur J Public Health 2017;27:530-7.

6 Ministry of Health and Welfare and Korea Centers for Disease Control and Prevention. Infectious diseases surveillance Yearbook, 2017, 2018.

7 Healthcare Bigdata Hub. Health insurance review and assessment service. Available: https://opendata.hira.or.kr/home.do

8 World Health Organization. Measles and rubella surveillance data. Available: https://www.who.int/immunization/monitoring surveillance/burden/vpd/surveillance_type/active/measles_ monthlydata/en/ 
9 Choe YJ, Eom H-E, Cho S-I. Trend of measles, mumps, and rubella incidence following the measles-rubella catch up vaccination in the Republic of Korea, 2001. J Med Virol 2017;89:1528-31.

$10 \mathrm{Heo}$ JY, Choe K-W, Yoon C-G, et al. Vaccination policy in Korean armed forces: current status and future challenge. J Korean Med Sci 2015;30:353-9.

11 Korea centers for disease control and prevention. Chapter XVI. Rubella. Available: https://nip.cdc.go.kr/irgd/reference.do

$12 \mathrm{Ki} \mathrm{M}, \mathrm{Kim} \mathrm{MH}$, Choi BY, et al. Rubella antibody loss rates in Korean children. Epidemiol Infect 2002;129:557-64.

13 Cho HK, Lee H, Kim HW, et al. Seroprevalences of specific IgG antibodies to measles, mumps, and rubella in Korean infants. $J$ Korean Med Sci 2016;31:1957-62.

$14 \mathrm{Ki}$ MR, Choi BY, Kim M-H, et al. Rubella seroprevalence in Korean children. J Korean Med Sci 2003;18:331-6.

15 Lee H, Kim HW, Cho HK, et al. Reappraisal of MMR vaccines currently used in Korea. Pediatr Int 2011;53:374-80.

16 Kim E-Y, Lee M-S. Related factors of age-appropriate immunization among urban-rural children aged 24-35 months in a 2005 population-based survey in Nonsan, Korea. Yonsei Med $J$ 2011;52:104-12.

17 Health Insurance Review \& Assessment Service. National health insurance statistical Yearbook 2017, 2018.

18 Bouthry E, Furione M, Huzly D, et al. Assessing Immunity to Rubella Virus: a Plea for Standardization of IgG (Immuno)assays. J Clin Microbiol 2016;54:1720-5.

19 World Health Organization. Manual for the laboratory-based surveillance of measles, rubella, and congenital rubella syndrome, 2019. Available: https://www.who.int/immunization/monitoring surveillance/burden/laboratory/manual section91/en/

20 Salathé $\mathrm{M}$, Jones JH. Dynamics and control of diseases in networks with community structure. PLoS Comput Biol 2010;6:e1000736.

$21 \mathrm{Xu} \mathrm{Z,} \mathrm{Zu} \mathrm{Z,} \mathrm{Zheng} \mathrm{T,} \mathrm{et} \mathrm{al.} \mathrm{Comparative} \mathrm{analysis} \mathrm{of} \mathrm{the} \mathrm{effectiveness}$ of three immunization strategies in controlling disease outbreaks in realistic social networks. PLoS One 2014;9:e95911.

22 Korea centers for disease control and prevention. 2017 disease control and prevention white paper, 2018.

23 Gallone MS, Gallone MF, Larocca AMV, et al. Lack of immunity against rubella among Italian young adults. BMC Infect Dis 2017:17:199

24 Sedgwick P. Bias in observational study designs: cross sectional studies. BMJ 2015;350:h1286.

25 Dimech W, Mulders MN. A review of testing used in seroprevalence studies on measles and rubella. Vaccine 2016;34:4119-22.

26 Schoub BD, Harris BN, McAnerney J, et al. Rubella in South Africa: an impending Greek tragedy? S Afr Med J 2009;99.

27 Inagaki ADdeM, Oliveira LARde, Oliveira MFBde, et al. [Seroprevalence of antibodies for toxoplasmosis, rubella, cytomegalovirus, syphilis and HIV among pregnant women in Sergipe]. Rev Soc Bras Med Trop 2009;42:532-6.

28 Artimos de Oliveira S, Bastos Camacho LA, Uzeda Barreto MC, et al Serologic status of women in an urban population in Brazil before and after rubella immunization campaign using routine screening data. $J$ Infect Dis 2011;204 Suppl 2:S664-8.

29 Avila Moura A, Mello MJGde, Correia JB. Serological statuses of pregnant women in an urban Brazilian population before and after the 2008 rubella immunization campaign. Vaccine 2016;34:445-50.

30 McElroy R, Laskin M, Jiang $D$, et al. Rates of rubella immunity among immigrant and non-immigrant pregnant women. J Obstet Gynaecol Can 2009;31:409-13.

31 Lim GH, Harris T, Desai S, et al. Rubella immunity among prenatal women in Ontario, 2006-2010. BMC Infect Dis 2013;13:362.

32 Lai FY, Dover DC, Lee B, et al. Determining rubella immunity in pregnant Alberta women 2009-2012. Vaccine 2015;33:635-41.

33 Madi N, Al-Tawalah $\mathrm{H}$, Abdul Khalik D, et al. A relatively high number of pregnant women in Kuwait remain susceptible to rubella: a need for an alternative vaccination policy. Med Princ Pract 2014;23:145-8.
34 Belefquih B, Kasouati J, Doblali T, et al. Rubella seroprevalence in pregnant women at the military teaching Hospital, Rabat, Morocco. Int J Gynaecol Obstet 2013;120:191-2.

35 Alsibiani SA. Rubella immunity among pregnant women in Jeddah, Western region of Saudi Arabia. Obstet Gynecol Int 2014;2014:659838.

36 Byrne L, Brant L, Reynolds C, et al. Seroprevalence of low rubella IgG antibody levels among antenatal women in England tested by NHS blood and transplant: 2004-2009. is rubella susceptibility increasing? Vaccine 2012;30:161-7.

37 Enders M, Bartelt U, Knotek F, et al. Performance of the Elecsys rubella IgG assay in the diagnostic laboratory setting for assessment of immune status. Clin Vaccine Immunol 2013;20:420-6.

38 O'Dwyer V, Bonham S, Mulligan A, et al. Antenatal rubella immunity in Ireland. Ir Med J 2013;106:232-5.

39 De Paschale M, Manco MT, Paganini A, et al. Rubella antibody screening during pregnancy in an urban area of northern Italy. Infect Dis Rep 2012;4:e17.

40 Vilajeliu A, García-Basteiro AL, Valencia S, et al. Rubella susceptibility in pregnant women and results of a postpartum immunization strategy in Catalonia, Spain. Vaccine 2015;33:1767-72.

41 Kakoulidou M, Forsgren M, Lewensohn-Fuchs I, et al. Serum levels of rubella-specific antibodies in Swedish women following three decades of vaccination programmes. Vaccine 2010;28:1002-7.

42 Tamer GS, Dundar D, Caliskan E. Seroprevalence of Toxoplasma gondii, rubella and cytomegalovirus among pregnant women in Western region of turkey. Clin Invest Med 2009;32:43-7.

43 Uysal A, Taner CE, Cüce M, et al. Cytomegalovirus and rubella seroprevalence in pregnant women in Izmir/Turkey: follow-up and results of pregnancy outcome. Arch Gynecol Obstet 2012;286:605-8.

44 Matthews LA, Lawrance LM, Gray D, et al. An audit of rubella IgG antibody status in antenatal women in a NHS trust over 5 years (2005-2009). Epidemiol Infect 2011;139:1720-6.

45 Ogundele M, Ghebrehewet S, Chawla A. Some factors affecting rubella seronegative prevalence among pregnant women in a North West England region between April 2011 and March 2013. J Public Health (Oxf) 2016;38:243-9.

46 Upreti SR, Thapa K, Pradhan YV, et al. Developing rubella vaccination policy in Nepal--results from rubella surveillance and seroprevalence and congenital rubella syndrome studies. J Infect Dis 2011;204(Suppl 1):S433-8.

47 Miyakawa M, Yoshino H, Yoshida LM, et al. Seroprevalence of rubella in the cord blood of pregnant women and congenital rubella incidence in Nha Trang, Vietnam. Vaccine 2014;32:1192-8.

48 Nardone A, Tischer A, Andrews N, et al. Comparison of rubella seroepidemiology in 17 countries: progress towards international disease control targets. Bull World Health Organ 2008;86:118-25.

49 Okuda M, Yamanaka M, Takahashi T, et al. Positive rates for rubella antibody in pregnant women and benefit of post-partum vaccination in a Japanese perinatal center. J Obstet Gynaecol Res 2008;34:168-73.

50 Hanaoka M, Hisano M, Watanabe N, et al. Changes in the prevalence of the measles, rubella, varicella-zoster, and mumps virus antibody titers in Japanese pregnant women. Vaccine 2013;31:2343-7.

51 Yamada T, Mochizuki J, Hanaoka M, et al. Effects of campaign for postpartum vaccination on seronegative rate against rubella among Japanese women. BMC Infect Dis 2014;14:152.

52 Liu F, Zhang S, Liu J, et al. Sociodemographic and economic characteristics of susceptibility to rubella among women preparing for pregnancy in rural China. Int $J$ Infect Dis 2017;62:112-8.

53 Lin C-C, Yang C-Y, Shih Y-L, et al. Rubella seroepidemiology and estimations of the catch-up immunisation rate and persistence of antibody titers in pregnant women in Taiwan. BJOG 2011:118:706-12.

54 Lin C-C, Yang C-Y, Shih Y-L, et al. Persistence and titer changes of rubella virus antibodies in primiparous women who had been vaccinated with strain RA 27/3 in junior high school. Clin Vaccine Immunol 2012;19:1-4. 